\title{
Are the current guidelines for surgical delay in hip fractures too rigid? A single center assessment of mortality and economics
}

\author{
Kristof Kempenaers ${ }^{\mathrm{a}}$, Ben Van Calster ${ }^{\mathrm{b}}$, Cindy Vandoren ${ }^{\mathrm{d}}$, An Sermon ${ }^{\mathrm{b}, \mathrm{c}}$, \\ Willem-Jan Metsemakers ${ }^{\mathrm{b}, \mathrm{c}}$, Paul Vanderschot ${ }^{\mathrm{b}, \mathrm{c}}$, Dominique Misselyn ${ }^{\mathrm{b}, \mathrm{c}}$, Stefaan Nijs ${ }^{\mathrm{b}, \mathrm{c}}$, \\ Harm Hoekstra ${ }^{\mathrm{b}, \mathrm{c}, *}$ \\ ${ }^{a} K U$ Leuven - University of Leuven, Faculty of Medicine, B-3000 Leuven, Belgium \\ ${ }^{\mathrm{b}} \mathrm{KU}$ Leuven - University of Leuven, Department of Development and Regeneration, B-3000 Leuven, Belgium \\ ${ }^{\mathrm{c}}$ University Hospitals Leuven, Department of Trauma Surgery, B-3000 Leuven, Belgium \\ ${ }^{\mathrm{d}}$ University Hospitals Leuven, Management Information and Reporting, B-3000 Leuven, Belgium
}

A R T I C L E I N F O

Keywords:

Proximal femoral fractures

Mortality

Economics

Surgical delay

\begin{abstract}
A B S T R A C T
Purpose: Controversy remains around acceptable surgical delay of acute hip fractures with current guidelines ranging from 24 to $48 \mathrm{~h}$. Increasing healthcare costs force us to consider the economic burden as well. We aimed to evaluate the adjusted effect of surgical delay for hip fracture surgery on early mortality, healthcare costs and readmission rate. We hypothesized that shorter delays resulted in lower early mortality and costs.

Methods: In this retrospective cohort study 2573 consecutive patients aged $\geq 50$ years were included, who underwent surgery for acute hip fractures between 2009 and 2017. Main endpoints were thirty- and ninety-day mortality, total cost, and readmission rate. Multivariable regression included sex, age and ASA score as covariates.

Results: Thirty-day mortality was $5 \%(\mathrm{n}=133)$, ninety-day mortality $12 \%(\mathrm{n}=304)$. Average total cost was $€ 11960$, dominated by hospitalization (59\%) and honoraria (23\%). Per 24 h delay, the adjusted odds ratio was 1.07 (95\% CI 0.98-1.18) for thirty-day mortality, 1.12 (95\% CI 1.04-1.19) for ninety-day mortality, and 0.99 (95\% CI =0.88-1.12) for readmission. Per 24 h delay, costs increased with $7 \%$ (95\% CI 6-8\%). For mortality, delay was a weaker predictor than sex, age, and ASA score. For costs, delay was the strongest predictor. We did not find clear cut-points for surgical delay after which mortality or costs increased abruptly.

Conclusions: Despite only modest associations with mortality, we observed a steady increase in healthcare costs when delaying surgery. Hence, a more pragmatic approach with surgery as soon as medically and organizationally possible seems justifiable over rigorous implementation of the current guidelines.
\end{abstract}

(C) 2018 Elsevier Ltd. All rights reserved.

\section{Introduction}

With an expected increase of $40 \%$ in the number of people aged 60 years and over during the next 20 years, and due to decreasing levels of physical activity, the incidence of osteoporotic proximal

Abbreviations: NICE, The National Institute for Health and Care Excellence; AO/ OTA, Arbeitsgemeinschaft für Osteosynthesefragen/American Orthopaedic Trauma Association; ASA, American Society of Anesthesiologists; LOS, length-of-stay; RCS, restricted cubic spline; AIC, akaike information criterion; BIC, Bayesian Information Criterion; IQR, interquartile range; $\mathrm{CI}$, confidence interval; OR, odds ratio.

* Corresponding author at: University Hospitals Leuven, Department of Trauma Surgery, Herestraat 49, B-3000 Leuven, Belgium.

E-mail address: harm.hoekstra@uzleuven.be (H. Hoekstra). femur fractures will dramatically rise in the upcoming decades [1]. Due to increased comorbidity in the elderly, as well as increased morbidity and mortality of hip fractures, these are considered as a major issue in our healthcare system.

Early surgery has been associated with better functional outcome, shorter hospital stay, less pain, lower nonunion rates and postoperative complications, yet the best timing of surgery remains controversial [2]. Several studies reported increased mortality with 24 to $48 \mathrm{~h}$ surgical delay [3-12] whereas some studies even advocate ultra-early surgery $(<12 \mathrm{~h})[13,14]$. In contrast, there are also studies that find no significant association between increased delay and mortality [15-20].

Since early hip surgery is acknowledged as a quality indicator in several guidelines, we have implemented a clinical pathway 
enhancing early surgery for hip fractures at the Department of Trauma Surgery of the University Hospitals Leuven in 2014 with success [21]. In order to justify our approach, we aimed to evaluate the association of surgical delay with several outcome measurements. We assessed the thirty- and ninety day mortality, healthcare costs, and readmission rate when treating AO type 31 hip fractures. We investigated the presence of a clear cut-point for surgical delay after which mortality and/or costs suddenly increase. We hypothesized that shorter delays resulted in lower early mortality and costs.

\section{Materials and methods}

\section{Study design}

Between January 1st 2009 and July 1st 2017 a total of 3070 consecutive patients were included in this retrospective cohort study. All patients were treated for an acute $(<3$ weeks) AO/OTA type 31 hip fracture (Arbeitsgemeinschaft für Osteosynthesefragen/American Orthopaedic Trauma Association) at the Department of Trauma Surgery of the University Hospitals Leuven. Follow-up was until October 1st 2017, resulting in a minimal follow-up time of 3 months. Patients aged $<50$ years $(n=164$, $5.3 \%$ ), as well as non-acute traumatic fractures, revision surgery, pathological fractures, hip surgery for avascular femoral head necrosis and coxarthrosis were excluded $(n=274,8.9 \%)$. Subsequently, 59 (1.9\%) patients had wrongly registered data, leaving 2573 patients. Clinical data was collected from the hospital's database KWS (Klinisch WerkStation) including age, sex, ASAscore, date and time of hospital admission, surgical delay, as well as the total and preoperative length-of-stay (LOS), and readmission within 3 months. Surgical delay was defined as the time between hospital admission and definitive surgery. Preoperative LOS was defined as the number of consecutive hospital admission days until hip surgery. Total LOS was defined as the number of consecutive hospital admission days. The time of death was obtained from the federal database (Kruispuntbank). The type of surgery was classified as either osteosynthesis (screw osteosynthesis, Proximal Femoral Nail [antirotation], $130^{\circ}$ hookplate, Dynamic Hip Screw) or hip arthroplasty (hemi and total). This study was completed in compliance with national legislation and the guidelines of the ethics committee of the University Hospitals Leuven.

\section{Healthcare costs}

The healthcare costs described in this paper relate to Belgian's healthcare financing context and are limited to costs induced by hospital-related care. The costs for each patient were extracted from the hospital's financial database and were composed of four categories: honoraria, materials, pharmaceuticals and hospitalization costs [22]. Honoraria mainly consist of fees related to medical activities, mainly based on a fee-for-service principle. Costs for pharmaceuticals consist of all used drugs and blood products the patient received during his stay. The hospitalization costs (cost of daily patient care) were calculated by multiplication of the lengthof-stay with the average national day based care fee (€441) [23]. All costs were corrected for inflation with reference to the last year of inclusion.

\section{Statistical analysis}

Main endpoints were thirty-day mortality, ninety-day mortality, and total healthcare cost. Secondary endpoints were readmission and cost categories (honoraria, pre-operative hospitalization, post-operative hospitalization, pharmaceuticals, and implants).
Correlations between surgical delay, age, and ASA score were computed using Spearman's rho. Because sex is dichotomous, correlations between sex and the other variables were computed using Pearson's r.

First, we performed a univariable (unadjusted) analysis of delay on the endpoints. Next, we performed a multivariable analysis to correct for the potential confounders age, gender and ASA-score. We did not dichotomize delay and age (except for descriptive statistics), but analyzed them as continuous variables. Mortality and readmission were modelled using logistic regression; costs were modeled using linear regression. To address potential nonlinearity in the relationship of surgical delay with the endpoints, we compared a linear relationship with a nonlinear relationship using restricted cubic splines (RCS) with 3,4 , or 5 knots to vary the allowed flexibility of the relationship [24]. We used the Bayesian Information Criterion (BIC) to select the preferred amount of flexibility. This approach allowed us to check whether there was any evidence of a cut-point after which mortality and/or costs suddenly increased more strongly. We evaluated regression diagnostics when modeling costs and observed that costs were best log-transformed. For logistic regression, relationships between predictors and outcomes were presented as odds ratios (OR; univariable analysis) or adjusted odds ratios (aOR; multivariable analysis). For linear regression, relationships between predictors and costs were expressed as average percentage increase in costs. Results of multivariable regression models were visualized with (1) nomograms in order to compare the predictor effects, and (2) plots showing the relationship of delay with the endpoint for the average patient (i.e. assuming average values for the confounding variables).

There were 14 patients with incomplete data (0.5\%), of which six had missing ASA score and 8 had missing implant costs. We used the 2559 complete cases for the regression modeling.

The statistical analysis was conducted with $\mathrm{R}$ version 3.4.1 [25], using the rms package for regression modeling and nomograms [24].

\section{Results}

Demographics, clinical characteristics and healthcare costs

The patient demographics and cost breakdown are summarized in Tables $1 \mathrm{a}$ and $1 \mathrm{~b}$. Within $48 \mathrm{~h}, 1962 / 2573$ (76\%) of the study patients underwent surgery. The median time to surgery was $25 \mathrm{~h}$ $(\mathrm{IQR}=16-47$, range $1-410)$. The median age was 82 years $(\mathrm{IQR}=74-$ 87). Surgical delay was not correlated with the potential confounders (correlation coefficients between -0.02 and 0.06 ).

Osteosynthesis procedures $(n=1642 ; 64 \%)$ dominated the arthroplasties $(n=931 ; 36 \%)$, in which hemi arthroplasty was the main procedure ( $88 \%$ vs. $12 \%$, hemi vs. total). A steady decline in hip osteosynthesis was observed with increased delay: 339/413 (82\%) when delay was $<12$ h vs $327 / 611$ (54\%) when delay was $>48 \mathrm{~h}$. In arthroplasty procedures, a trend was found in favor of total arthroplasty with increased surgical delay: $1 / 74$ (1\%) when delay was $<12$ h vs 50/284 (18\%) when delay was $>48 \mathrm{~h}$.

The median LOS was 13 days (IQR = 9-19, range $1-342$ ). Thirtyday mortality was $5 \%(n=133)$ and ninety-day mortality was $12 \%$ $(\mathrm{n}=304)$. Hospital readmissions within 3 months were infrequent $(\mathrm{n}=126 ; 5 \%)$ and occurred after a median of 22 days (IQR $=7-43$ ).

\section{Association between surgical delay and thirty-day mortality}

The relationships of delay and age with thirty-day mortality were best described with a linear effect. Unadjusted for the confounders, surgical delay had an OR of $1.11(95 \% \mathrm{CI}=1.02-1.22)$ per $24 \mathrm{~h}$. In multivariable analysis, the aOR was 1.07 (95\% CI=0.98-1.18) 
Table 1a

Descriptive statistics. (a) Demographics sorted by surgical delay $(n=2573)$.

\begin{tabular}{|c|c|c|c|c|c|c|c|}
\hline $\mathrm{N}$ & $\begin{array}{c}\leq 12 \mathrm{~h} \\
413(16 \%)\end{array}$ & $\begin{array}{c}12 \leq 24 h \\
826(32 \%)\end{array}$ & $\begin{array}{l}24 \leq 36 h \\
346(13 \%)\end{array}$ & $\begin{array}{l}36 \leq 48 h \\
377(15 \%)\end{array}$ & $\begin{array}{l}48 \leq 72 h \\
336(13 \%)\end{array}$ & $\begin{array}{c}>72 \mathrm{~h} \\
275(11 \%)\end{array}$ & $\begin{array}{l}\text { Total } \\
2573\end{array}$ \\
\hline \multicolumn{8}{|l|}{ Sex } \\
\hline Female & 270 & 587 & 240 & 264 & 250 & 179 & $1790(70 \%)$ \\
\hline Male & 143 & 239 & 106 & 113 & 86 & 96 & 783 (30\%) \\
\hline \multicolumn{8}{|l|}{ Age } \\
\hline 50-59 & 46 & 62 & 17 & 20 & 16 & 12 & $173(7 \%)$ \\
\hline $60-69$ & 39 & 89 & 42 & 43 & 48 & 24 & $285(11 \%)$ \\
\hline $70-79$ & 77 & 190 & 86 & 100 & 84 & 70 & 607 (24\%) \\
\hline $80-89$ & 171 & 363 & 148 & 177 & 147 & 136 & $1142(44 \%)$ \\
\hline$\geq 90$ & 80 & 122 & 53 & 37 & 41 & 33 & $366(14 \%)$ \\
\hline \multicolumn{8}{|l|}{ ASA-score } \\
\hline 1 & 16 & 23 & 6 & 6 & 8 & 3 & $62(2 \%)$ \\
\hline 2 & 149 & 279 & 109 & 152 & 125 & 64 & $878(34 \%)$ \\
\hline 3 & 227 & 480 & 211 & 203 & 187 & 180 & $1488(58 \%)$ \\
\hline $4-5$ & 19 & 42 & 18 & 16 & 16 & 28 & 139 (5\%) \\
\hline
\end{tabular}

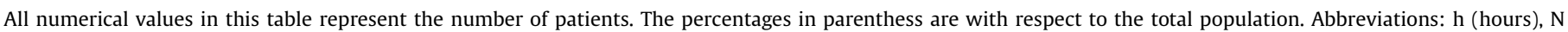
(number), ASA (American Society of Anesthesiologists).

(Table 2). Converted per hour, this means a $0.3 \%$ increase in odds per hour increase in delay. Fig. 1 a shows the estimated risk of thirty-day mortality by delay for a patient with average values for the confounding variables. The confounding variables had a stronger relationship with mortality than surgical delay (Table 2, Fig. 1b). Age, ASA-score and sex were the most important predictors of thirty-day mortality: the effects of male sex, ASA 3 score, or age 65 years were approximately equal to the effect of a delay of around $250-300 \mathrm{~h}$ (Fig. 1b).

\section{Association between surgical delay and ninety-day mortality}

Results for ninety-day mortality were comparable to results for thirty-day mortality. Delay and age were best modeled with a linear effect. The unadjusted OR was $1.16(95 \% \mathrm{CI}=1.09-1.23)$ per $24 \mathrm{~h}$, the aOR was $1.12(95 \% \mathrm{CI}=1.04-1.19)$ per $24 \mathrm{~h}$ (Table 2, Fig. 1c). This corresponds to $0.5 \%$ increase in odds per hour increase in delay. The effects of the confounding variables were stronger, although the difference was smaller than for thirty-day mortality. The effect of male sex or age 65 years was similar to the effect of a delay of around $200 \mathrm{~h}$ and the effect of ASA 3 score was comparable to the effect of 350-400 h of delay (Fig. 1d).

\section{Association of surgical delay with total costs and cost categories}

Delay was best modeled with a linear effect and age with a nonlinear effect (RCS with 3 knots) on the log-transformed costs. The log-transformation allowed to express relationships with total costs in terms of percentages (Table 3 ). In univariable analysis, each 24 h delay was associated with an $8 \%(95 \% \mathrm{CI}=7-9 \%)$ increase in costs. In multivariable analysis, costs increased with $7 \%(95 \%$ $\mathrm{CI}=6-8 \%$ ) per $24 \mathrm{~h}$ delay (Table 3 ). This means, for example, that a delay of 72 h was associated with $15 \%$ higher costs $(95 \% \mathrm{CI}=12-$ $18 \%$ ) than a delay of $24 \mathrm{~h}$. The relationship between delay and total

\section{Table 1b}

Hospital related costs per patient and total $(n=2573)$.

\begin{tabular}{lcclc}
\hline Category & Median & Mean & Range & Relative share (mean) \\
\hline Pharmaceuticals & $€ 369$ & $€ 736$ & $€ 29-264,757$ & $6.2 \%$ \\
Honoraria & $€ 2069$ & $€ 2794$ & $€ 151-35,909$ & $23.4 \%$ \\
Implants & $€ 1053$ & $€ 1357$ & $€ 81-11,913$ & $11.3 \%$ \\
Hospitalization & $€ 5601$ & $€ 7077$ & $€ 296-150,619$ & $59.2 \%$ \\
Total & $€ \mathbf{9 5 3 3}$ & $€ \mathbf{1 1 , 9 6 0}$ & $€ \mathbf{1 9 5 8 - 2 8 6 , 5 1 0}$ &
\end{tabular}

Costs in this table concern the corrected costs for inflation with respect to the last year of inclusion; 2017. costs for an average patient is visualized in Fig. 2a. Delay had the strongest relationship with total costs (Fig. 2b). Sex was hardly related to total cost. Total costs were estimated to be highest at the age of 80 years, and lower at younger or older ages. The effect of the age of 80 years is similar to the effect of a delay of around $130 \mathrm{~h}$ (Fig. 2b).

Furthermore, we estimated the relationship of delay to different components of the total cost (Fig. 2c). The cost of implants appeared as expected to be largely unaffected by the delay. Pharmaceuticals and honoraria also had a weak relationship. In contrast, pre- and postoperative hospitalization costs increased with increasing delay.

\section{Association between surgical delay and readmission}

Delay was modeled with a linear relationship on readmission. The unadjusted OR was $1.00(95 \% \mathrm{CI}=0.88-1.12)$ per $24 \mathrm{~h}$ delay. In multivariable analysis, the aOR was $0.99(95 \% \mathrm{CI}=0.88-1.12)$ (Fig. 3).

\section{Discussion}

With the introduction of the quality indicator early surgery at our department and the controversy for surgical delay of acute hip fractures, we investigated the association of surgical delay with mortality and costs in order to justify our approach. In contrast to other studies about the effect of delayed surgery on mortality, delayed surgery was analyzed here as a continuous variable. Testing delayed surgery for significance on the outcome, using multiple different cut points to define 'delayed', does not match reality and causes methodological problems such as multiple testing and overfitting [26]. We used splines to model the relationship between delay and mortality/costs, and could not identify a clear cut-point for delayed surgery with regard to the outcomes. We included those confounding variables that hypothetically could affect the early mortality $[2,12]$. Other variables, which influence the morbidity (and mortality) after hip surgery, such as frailty, precise comorbidities, and the impact of a multidisciplinary hip fracture program were not included.

Early surgery was introduced as a quality indicator at our institution in 2014 with a clear impact on average delay of surgery in elderly ( $\geq 65$ year). Before 2014, approximately $45 \%$ of these patients underwent surgery within the next calendar day after admission. After the implementation this increased to $85 \%$ 
Table 2

Effects of variables on mortality.

\begin{tabular}{|c|c|c|c|c|}
\hline \multirow[t]{2}{*}{ Predictor } & \multicolumn{2}{|c|}{ Thirty-day mortality } & \multicolumn{2}{|c|}{ Ninety-day mortality } \\
\hline & Coeff (SE) & OR $(95 \% \mathrm{CI})$ & Coeff (SE) & OR $(95 \% \mathrm{CI})$ \\
\hline Delay, per $24 \mathrm{~h}$ & $0.071(0.046)$ & $1.07(0.98-1.18)$ & $0.11(0.034)$ & $1.12(1.04-1.19)$ \\
\hline Male & $0.93(0.19)$ & $2.53(1.75-3.67)$ & $0.92(0.14)$ & $2.51(1.92-3.27)$ \\
\hline \multicolumn{5}{|l|}{ ASA } \\
\hline 1 & $-0.72(1.03)$ & $0.49(0.06-3.63)$ & $-1.77(1.02)$ & $0.17(0.02-1.26)$ \\
\hline 2 & $-0.78(0.26)$ & $0.46(0.28-0.77)$ & $-1.32(0.20)$ & $0.27(0.18-0.40)$ \\
\hline 3 & Reference & 1 & Reference & 1 \\
\hline 4 & $1.15(0.26)$ & $3.17(1.91-5.25)$ & $1.19(0.20)$ & $3.28(2.22-4.86)$ \\
\hline Age, per 10 years & $0.62(0.12)$ & $1.86(1.48-2.33)$ & $0.62(0.081)$ & $1.86(1.58-2.18)$ \\
\hline
\end{tabular}

The first column represents the coefficients of the variable in the statistical model.

The values in the second column are odds ratios with the 95\% confidence interval in parenthesis.

Abbreviations: SE (Standard Error), OR (Odds Ratio), CI (Confidence Interval), ASA (American Society of Anesthesiologists).

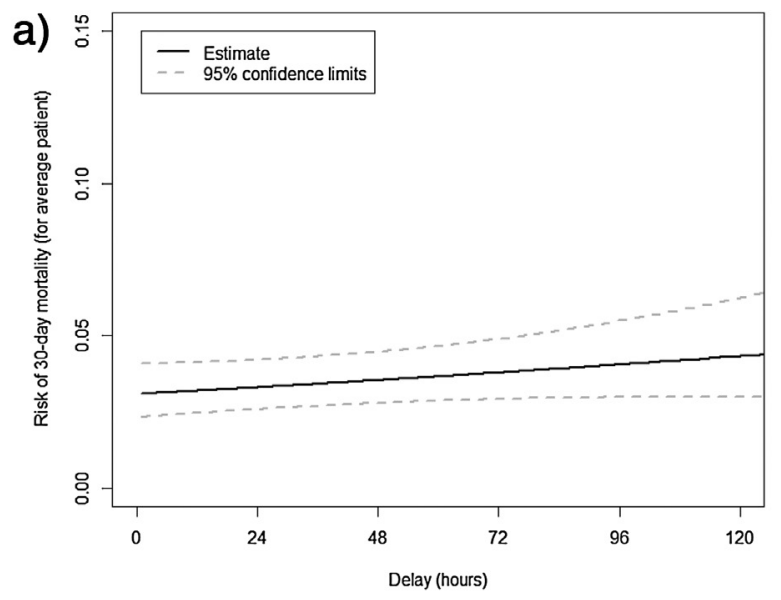

b)

Points

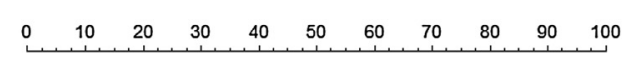

Delay (hours)

$\begin{array}{lllll}0 & 100 & 200 & 300 \quad 400\end{array}$

Male

ASA

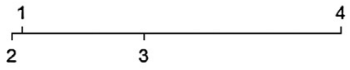

Age (years)

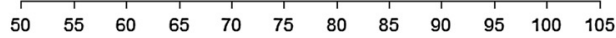

Total Points

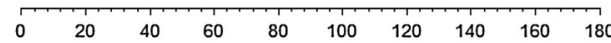

Risk of death within 30 days

$$
\begin{array}{llllllll}
0.01 & 0.02 & 0.05 & 0.1 & 0.2 & 0.3 & 0.4 & 0.5
\end{array}
$$

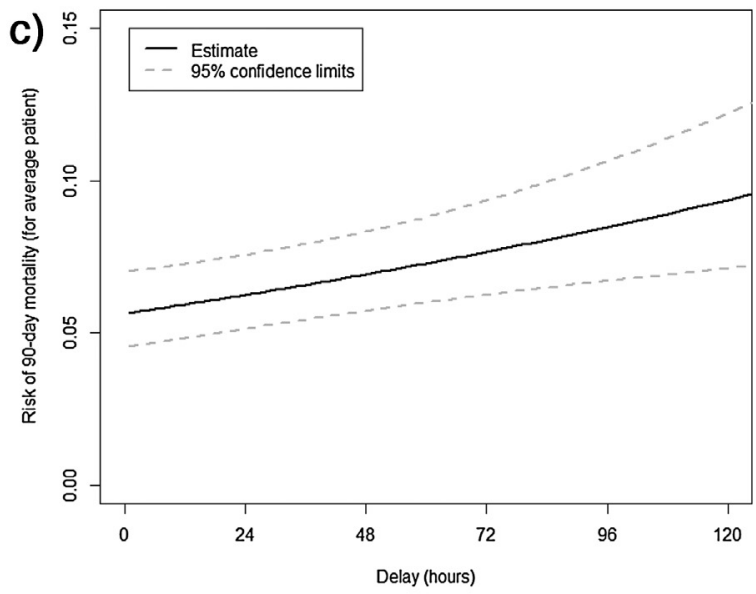

d)

Points

$\begin{array}{lllllllllll}0 & 10 & 20 & 30 & 40 & 50 & 60 & 70 & 80 & 90 & 100\end{array}$

Delay (hours)

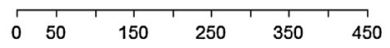

Male

ASA

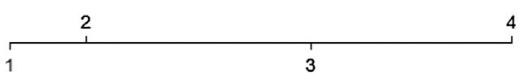

Age (years)

$\begin{array}{llllllllllll}50 & 55 & 60 & 65 & 70 & 75 & 80 & 85 & 90 & 95 & 100 & 105\end{array}$

Total Points

$\begin{array}{lllllllllllll}0 & 20 & 40 & 60 & 80 & 100 & 120 & 140 & 160 & 180 & 200 & 220 & 240\end{array}$

Risk of death within 90 days

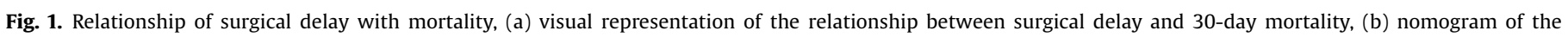

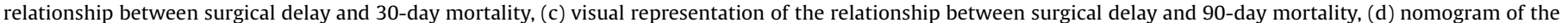
relationship between surgical delay and 90-day mortality.

(data not shown). With up-to-date guidelines concerning the preoperative management of coagulants and the introduction of newer antidotes, surgery within $48 \mathrm{~h}$ after admission is possible in most patients. In contrast, the relative large number of patients that were treated delayed before 2014, presented an excellent opportunity to measure the effect of delayed surgery on mortality, total healthcare costs, and readmission.

Opponents of early surgery suggest that delay can be acceptable for stabilizing geriatric patients, since these patients present with more comorbidities and polypharmacy, and account for the most 
Table 3

Effects of variables on total costs.

\begin{tabular}{lcc}
\hline Predictor & Coeff $(\mathrm{SE})$ for $\log ($ total cost $)$ & Effect on total cost \\
\hline Delay & & \\
$\quad$ Per $24 \mathrm{~h}$ & $0.068(0.0064)$ & $+7 \%(+6$ to +8$)$ \\
$48 \mathrm{~h}$ vs $24 \mathrm{~h}$ & $0.068(0.0064)$ & $+7 \%(+6$ to +8$)$ \\
$72 \mathrm{~h}$ vs $24 \mathrm{~h}$ & $0.14(0.013)$ & $+15 \%(+12$ to +18$)$ \\
$96 \mathrm{~h}$ vs $24 \mathrm{~h}$ & $0.21(0.019)$ & $+23 \%(+18$ to +28$)$ \\
$144 \mathrm{~h}$ vs $24 \mathrm{~h}$ & $0.34(0.032)$ & $+41 \%(+33$ to +50$)$ \\
$192 \mathrm{~h}$ vs $24 \mathrm{~h}$ & $0.48(0.045)$ & $+62 \%(+48$ to +77$)$ \\
Male & $0.021(0.022)$ & $+2 \%(-2$ to +7$)$ \\
ASA & & \\
1 & $-0.35(0.065)$ & $-29 \%(-38$ to -20$)$ \\
2 & $-0.12(0.021)$ & $-11 \%(-15$ to -7$)$ \\
3 & Reference & $+19 \%(9$ to +29$)$ \\
4 & $0.17(0.044)$ & \\
Age, per 10 years & & $+15 \%(+11$ to +19$)$ \\
60 y vs $50 \mathrm{y}$ & $0.14(0.019)$ & $+32 \%(+22$ to +42$)$ \\
70 y vs $50 \mathrm{y}$ & $0.28(0.037)$ & $+42 \%(+29$ to +55$)$ \\
$80 \mathrm{y}$ vs $50 \mathrm{y}$ & $0.35(0.047)$ & $+35 \%(+24$ to +47$)$ \\
$90 \mathrm{y}$ vs $50 \mathrm{y}$ & $0.30(0.043)$ & $+23 \%(+12$ to +35$)$ \\
$100 \mathrm{y}$ vs $50 \mathrm{y}$ & $0.21(0.049)$ &
\end{tabular}

The first column represents the coefficients of the variable in the statistical model The numbers in the second column are relative increases with respect to a reference value, expressed in percentages.

Abbreviations: SE (Standard Error), log (logarithm), ASA (American Society of Anesthesiologists)

frail patients admitted to the hospital, while proponents of early surgery emphasize the reduced complication rate [2,27]. In addition, no increase in perioperative mortality or blood loss associated with early surgery for geriatric patients on antiplatelet therapy was observed [28]. Our complication registration over time was incomplete and therefore not included. Nonetheless, we observed no increase in readmission rate with increased delay, providing crude information on the quality of surgery. The readmission rate concerned readmission to the University Hospitals Leuven and readmissions to other hospitals were not accounted for. Therefore, this rate might be underestimated.

The time to surgery in this study was calculated from time of admission at the emergency services until start of surgery. Other studies calculate from time of radiographic diagnosis or time of accident $[11,29]$. However, the definition applied in this study is most obvious, since the time between the accident and admission to the hospital cannot be addressed by the hospital organization and therefore is not accounted as a modifiable quality marker.

The incidence of hip fractures in the Belgian population aged 50 years and over, was reported 394 in 100,000 with a higher risk in women and elderly aged 75 years and over [30]. These findings are affirmed in our descriptive statistics. The observed thirty-day and ninety-day mortality observed in our study population were rather low ( $5 \%$ and $12 \%$, respectively), though in line with recent literature [12,31].

The distribution of healthcare costs was equal to what we have shown previously for the treatment of tibial fractures, wherein the total healthcare costs are mainly driven by the LOS [22]. With the continuing increase in healthcare costs and the rapid gaining importance of health economics, it seems justified to include the economic burden in decision-making about the surgical treatment of hip fractures. However, since healthcare financing is countryspecific, data and conclusions from this study cannot simply be compared linearly, without taking the differences in healthcare financing into account. The financing of Belgian hospitals is a shared effort of the health insurance system, the Ministry of Health and individual contributions that serve as copayment. Two main categories in hospital financing can be distinguished: fee for service payments and lump sum payments based on a fixed/closed national budget (medical activities and nonmedical services). The a)

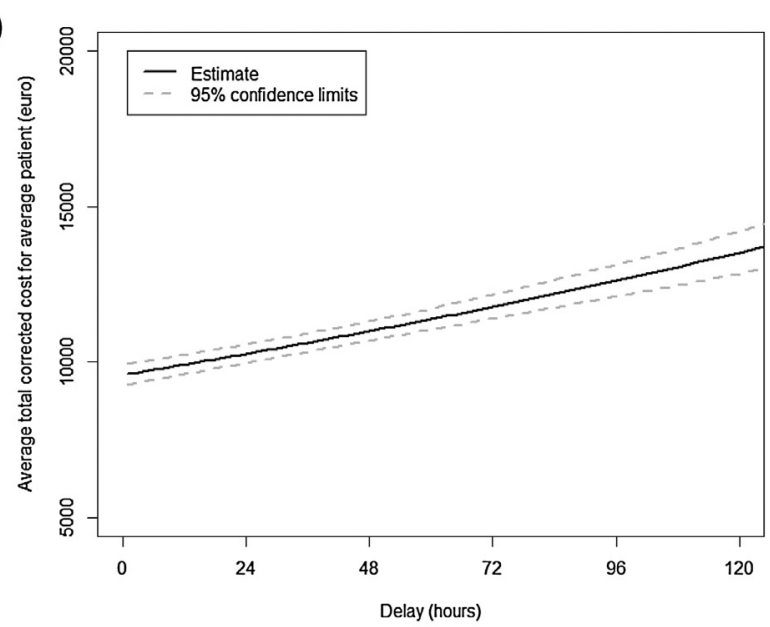

b)

Points

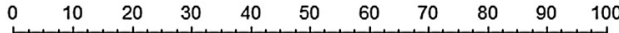

Delay (hours)

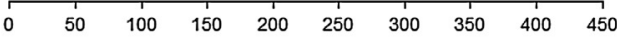

Male

$\int_{1}^{0}$

ASA

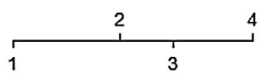

Age (years)

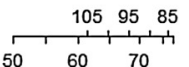

Total Points

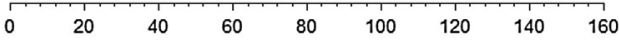

Predicted cost (euro)

10000

$20000 \quad 30000$

c)

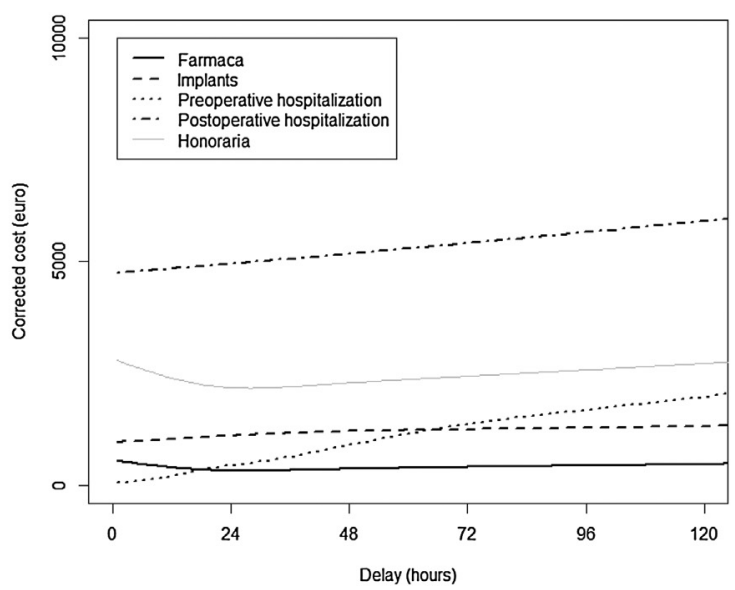

Fig. 2. Relationship of surgical delay with total costs, (a) visual representation of the relationship between surgical delay and total costs, (b) nomogram of the relationship between surgical delay and total costs, (c) visual representation of the relationship between surgical delay and differentiation of costs. 


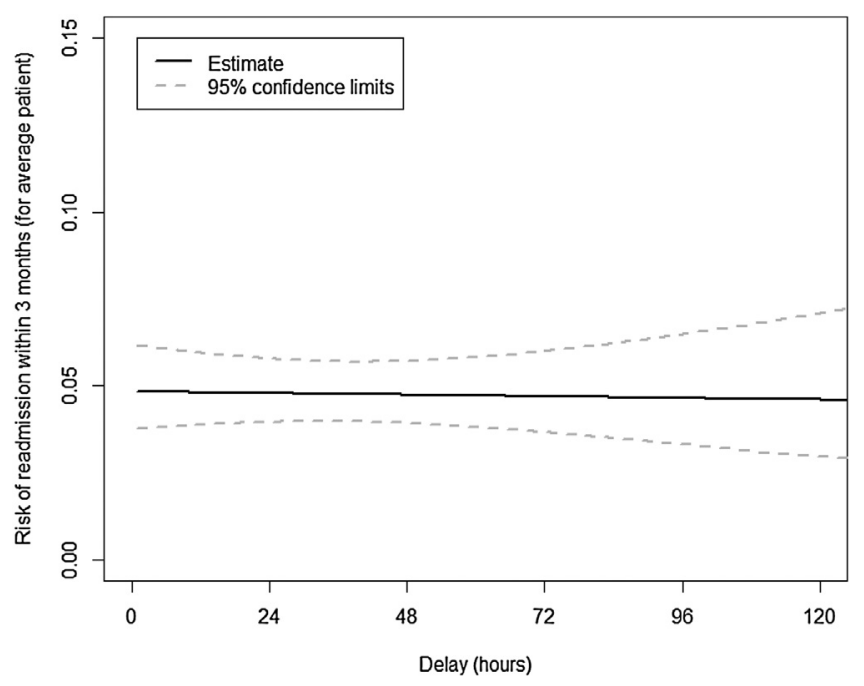

Fig. 3. Relationship of surgical delay with readmission rate.

medical activities are charged by the hospital as a fee-for-service system based on a fixed price set on the national level. The (nonmedical services) costs related to the hospital stay are only reimbursed based on the national average LOS for specific diseases and interventions, and can be adjusted for the severity of illness. The costs included in this study represent the hospital funds for patient care. Total reimbursements of hospitals takes place on a macro scale and is not bound by specific pathologies, as under- and overcompensation of pathologies balance out the total reimbursement, which can be seen as an approximation of the total costs of care for society.

In conclusion, increased risk of mortality could only be associated with surgical delay well beyond the current guidelines of forty-eight hours. We could not identify a clear cut-point for delayed surgery with regard to the outcomes. Patient-specific risk factors like age, sex and ASA-score were much stronger predictors of early mortality than surgical delay. Nevertheless, these are unmodifiable. In contrast, the total healthcare costs steadily increased with prolonged surgical delay. Therefore, the small increase in odds per hour increase in delay for both the thirty and ninety-days mortality, but also the steady increase in total healthcare costs, advocate a pragmatic approach with hip surgery as soon as medically possible. Since ultra-early surgery has not shown to benefit the outcomes, urgent planning of surgery is appropriate but performing surgery on unconventional hours does not seem necessary. Moreover, no relation was observed between delayed surgery and readmission rate. Since the readmission rate only partially reflects the quality of surgery however, further research should focus on the quality of surgery (i.e. complication rate) with respect to surgical delay.

\section{Conflict of interest}

The authors declare that they have no conflict of interest.

\section{Funding}

There is no funding source.

\section{Ethical approval}

This article does not contain any studies with human participants or animals performed by any of the authors.

\section{Informed consent}

There was no informed consent obtained from individual participants included in the study.

\section{References}

[1] Hernlund E., Svedbom A, Ivergård M, Compston J, Cooper C, Stenmark J, et al Osteoporosis in the European Union: medical management, epidemiology and economic burden. Arch Osteoporos 2013;8(1-2):136, doi:http://dx.doi.org/ 10.1007/s11657-013-0136-1.

[2] Librero J, Peiro S, Leutscher E, Merlo J, Bernal-Delgado E, Ridao M, et al. Timing of surgery for hip fracture and in-hospital mortality: a retrospective population-based cohort study in the Spanish National Health System. BMC Health Serv Res 2012;12(1):15, doi:http://dx.doi.org/10.1186/1472-6963-1215.

[3] Shiga T, Wajima Z, Ohe Y. Is operative delay associated with increased mortality of hip fracture patients? Systematic review, meta-analysis, and meta-regression. Can J Anaesth 2008;55(3):146-54, doi:http://dx.doi.org/ 10.1007/BF03016088

[4] Moja L, Piatti A, Pecoraro V, Ricci C, Virgili G, Salanti G, et al. Timing matters in hip fracture surgery: patients operated within 48 hours have better outcomes. a meta-analysis and meta-regression of over 190,000 patients. PLoS One 20127 (10), doi:http://dx.doi.org/10.1371/journal.pone.0046175.

[5] Simunovic N, Devereaux PJ, Sprague S, Guyatt GH, Schemitsch E, Debeer J, et al Effect of early surgery after hip fracture on mortality and complications: systematic review and meta-analysis. CMAJ 2010;182(15):1609-16, doi:http:// dx.doi.org/10.1503/cmaj.092220.

[6] Elliott J, Beringer T, Kee F, Marsh D, Willis C, Stevenson M. Predicting survival after treatment for fracture of the proximal femur and the effect of delays to surgery. J Clin Epidemiol 2003;56(8):788-95, doi:http://dx.doi.org/10.1016/ S0895-4356(03)00129-X.

[7] Novack V, Jotkowitz A, Etzion O, Porath A. Does delay in surgery after hip fracture lead to worse outcomes? A multicenter survey. Int J Qual Heal Care 2007;19(3):170-6, doi:http://dx.doi.org/10.1093/intqhc/mzm003.

[8] McGuire KJ, Bernstein J, Polsky D, Silber JH. The 2004 Marshall Urist award: delays until surgery after hip fracture increases mortality. Clin Orthop Relat Res 2004;2004(428):294-301, doi:http://dx.doi.org/10.1097/01. blo.0000146743.28925.1c

[9] Moran CG, Wenn RT, Sikand M, Taylor AM. Early mortality after hip fracture: is delay before surgery important? J Bone Joint Surg Am 2005;87:483-9, doi: http://dx.doi.org/10.2106/JBJS.D.01796.

[10] Weller I, Wai EK, Jaglal S, Kreder HJ. The effect of hospital type and surgical delay on mortality after surgery for hip fracture. J Bone Joint Surg Br 2005;87 (3):361-6, doi:http://dx.doi.org/10.1302/0301-620X.87B3.

[11] Nyholm AM, Gromov K, Palm H, Brix M, Kallemose T, Troelsen A. Time to surgery is associated with thirty-day and ninety-day mortality after proximal femoral fracture: a retrospective observational study on prospectively collected data from the danish fracture database collaborators. J Bone Joint Surg Am 2015;97(16):1333-9, doi:http://dx.doi.org/10.2106/JBJS.0.00029.

[12] Morrissey N, Iliopoulos E, Osmani AW, Newman K. Neck of femur fractures in the elderly: does every hour to surgery count? Injury 2017;48(6):1155-8, doi: http://dx.doi.org/10.1016/j.injury.2017.03.007.

[13] Uzoigwe CE, Burnand HGF, Cheesman CL, Aghedo DO, Faizi M, Middleton RG. Early and ultra-early surgery in hip fracture patients improves survival. Injury 2013;44(6):726-9, doi:http://dx.doi.org/10.1016/j.injury.2012.08.025.

[14] Bretherton CP, Parker MJ. Early surgery for patients with a fracture of the hip decreases 30-day mortality. Bone Joint J 2015;97-B(1):104-8, doi:http://dx. doi.org/10.1302/0301-620X.97B1.

[15] Grimes JP, Gregory PM, Noveck H, Butler MS, Carson JL. The effects of time-tosurgery on mortality and morbidity in patients following hip fracture. Am J Med 2002;112(9):702-9, doi:http://dx.doi.org/10.1016/S0002-9343(02) 01119-1.

[16] Smektala R, Endres HG, Dasch B, Maier C, Trampisch HJ, Bonnaire F, et al. The effect of time-to-surgery on outcome in elderly patients with proximal femoral fractures. BMC Musculoskelet Disord 2008;9:171, doi:http://dx.doi. org/10.1186/1471-2474-9-171.

[17] Holt G, Smith R, Duncan K, Finlayson DF, Gregori A. Early mortality after surgical fixation of hip fractures in the elderly: an analysis of data from the Scottish hip fracture audit. J Bone Jt Surg Br 2008;90-B(10):1357-63, doi: http://dx.doi.org/10.1302/0301-620x.90b10.21328.

[18] Siegmeth AW, Gurusamy K, Parker MJ, Gurusamy K. Delay to surgery prolongs hospital stay in patients with fractures of the proximal femur. J Bone Jt Surg [Br] 2005;8787(8):1123-6, doi:http://dx.doi.org/10.1302/0301-620X.87B8.

[19] Franzo A, Francescutti C, Simon G. Risk factors correlated with post-operative mortality for hip fracture surgery in the elderly: a population-based approach. Eur J Epidemiol 2005;20(12):985-91, doi:http://dx.doi.org/10.1007/s10654005-4280-9.

[20] Khan SK, Kalra S, Khanna A, Thiruvengada MM, Parker MJ. Timing of surgery for hip fractures: a systematic review of 52 published studies involving 291,413 patients. Injury 2009;40(7):692-7, doi:http://dx.doi.org/10.1016/j. injury.2009.01.010. 
[21] NICE (National Institute for Health and Clinical Excellence). NICE guideline 124, Hip fracture: the management of hip fracture in adults. http://guidance. nice.org.uk/CG124. (Accessed April 26, 2017).

[22] Metsemakers W-J, Smeets B, Nijs S, Hoekstra H. Infection after fracture fixation of the tibia: analysis of healthcare utilization and related costs. Injury 2017;48 (6):1204-10. http://doi.org/10.1016/j.injury.2017.03.030.

[23] (RIZIV) R voor ZI. Verpleegdagprijzen Ziekenhuizen. http://www.riziv.fgov.be $\mathrm{nl} /$ themas/kost-terugbetaling/door-ziekenfonds/verzorging-ziekenhuizen/ Paginas/verpleegdagprijzen-ziekenhuizen.aspx\#.WNViFzs1908. (Accessed December 23, 2016).

[24] Harrell FE. Regression Modeling Strategies 201564:, doi:http://dx.doi.org/ 10.1007/978-1-4757-3462-1.

[25] The R foundation. The R-project for Statistical Computing, version 3.3.1. 2017. https://www.r-project.org/.

[26] Bennette C, Vickers A. Against quantiles: categorization of continuous variables in epidemiologic research, and its discontents. BMC Med Res Methodol 2012;12, doi:http://dx.doi.org/10.1186/1471-2288-12-21.

[27] Ventura C, Trombetti S, Pioli G, Belotti LMB, De Palma R. Impact of multidisciplinary hip fracture program on timing of surgery in elderly patients. Osteoporos Int 2014;25(11):2591-7, doi:http://dx.doi.org/10.1007/ s00198-014-2803-5.

[28] Sa-Ngasoongsong P, Kulachote N, Sirisreetreerux N, Chanplakorn P, Laohajaroensombat S, Pinsiranon N, et al. Effect of early surgery in high surgical risk geriatric patients with femoral neck fracture and taking antiplatelet agents. World J Orthop 2015;6(11):970-6, doi:http://dx.doi.org/ 10.5312/wjo.v6. i11.970.

[29] Orosz GM, Magaziner J, Hannan EL, Morrison RS, Koval K, Gilbert M, et al. Association of timing of surgery for hip fracture and patient outcomes. JAMA 2004;291(14):1738-43, doi:http://dx.doi.org/10.1001/jama.291.14.1738.

[30] Hiligsmann M, Bruyère O, Roberfroid D, Dubois C, Parmentier Y, Carton J, et al. Trends in hip fracture incidence and in the prescription of antiosteoporosis medications during the same time period in Belgium (2000-2007). Arthritis Care Res 2012;64(5):744-50, doi:http://dx.doi.org/10.1002/acr.21607.

[31] Giannoulis D, Calori GM, Giannoudis PV. Thirty-day mortality after hip fractures: has anything changed? Eur J Orthop Surg Traumatol 2016;26 (4):365-70, doi:http://dx.doi.org/10.1007/s00590-016-1744-4. 